\title{
Exhibiting the Online World: A Case Study
}

\author{
Marc Weber \\ Internet History Program Founder and Curator, Computer History Museum, Mountain View, \\ California, USA \\ marc@webhistory.org
}

\begin{abstract}
The online world and its origins is one of the most obviously relevant areas of computing history to the general public. It is also one of the hardest to effectively interpret and display. This paper discusses the challenges of exhibiting the complex and mostly intangible online world - sometimes called "cyberspace" - in a museum context. These include not just display challenges, but also the difficulties of framing this complex, wide ranging, and largely unknown history in an accessible way. It presents some of the techniques we've developed as solutions at the Computer History Museum, with the hope they may contribute to an exchange of ideas. These techniques are still evolving. The three relevant galleries in our permanent exhibition form the first comprehensive exhibit on the history of the online world. A current temporary exhibit and five small permanent ones in development focus on specific areas of cyberspace.
\end{abstract}

Keywords: Online, Web history, Internet history, networking history, cyberspace, computer history, exhibit, museum, social media, Computer History Museum, computer, telecommunications.

\section{Introduction}

"Writing about music is like dancing about architecture" - origin uncertain, often attributed to Martin Mull

Of all the areas of computing and telecommunications history, the online world is perhaps the most obviously and personally relevant to a wide variety of audiences. Whether you're a Maasai tribesman buying and selling cattle on your mobile phone, or a Norwegian bride walking to the altar with the groom you met online, it is hard to think of an area of modern life that is not being radically changed by the Web, the Internet, and mobile data. It is also hard to think of a field where even the wilder hyperbole about its importance has a better chance of turning out true.

When it comes to making online history relevant, that's the good news. The bad news is that the mercurial, complex, immaterial reaches of cyberspace are some of the hardest subjects to pin down and effectively display.

There are two main problems. First, the online world is insubstantial and more of a process than a thing, offering few easily exhibitable forms. Second, it's complicated. 
The same wide-reaching impacts that make cyberspace important also mean that even its simplest stories quickly involve different technologies, and geographies, and politics. Telling them often requires a heavy burden of context and framing "backstories" just to make them intelligible.

A further wrinkle is that many people barely realize the online world has a history at all, or that its predecessors have potential lessons to teach us that go far beyond computing and touch on the most basic ways we share, navigate, and create knowledge.

At the Computer History Museum, we grappled with all of the issues above when we developed our permanent exhibition "Revolution: The First 2000 Years of Computing," which opened at the start of 2011. Taken together the "Networking and the Web" and "Mobile Computing" galleries, which I curated, form the first comprehensive exhibit on the origins of the online world. The parallel Web version of the exhibition ${ }^{1}$ contains all of the same content plus more. We've continued to refine our palette of techniques with a temporary exhibit on the origins of "surrogate travel"

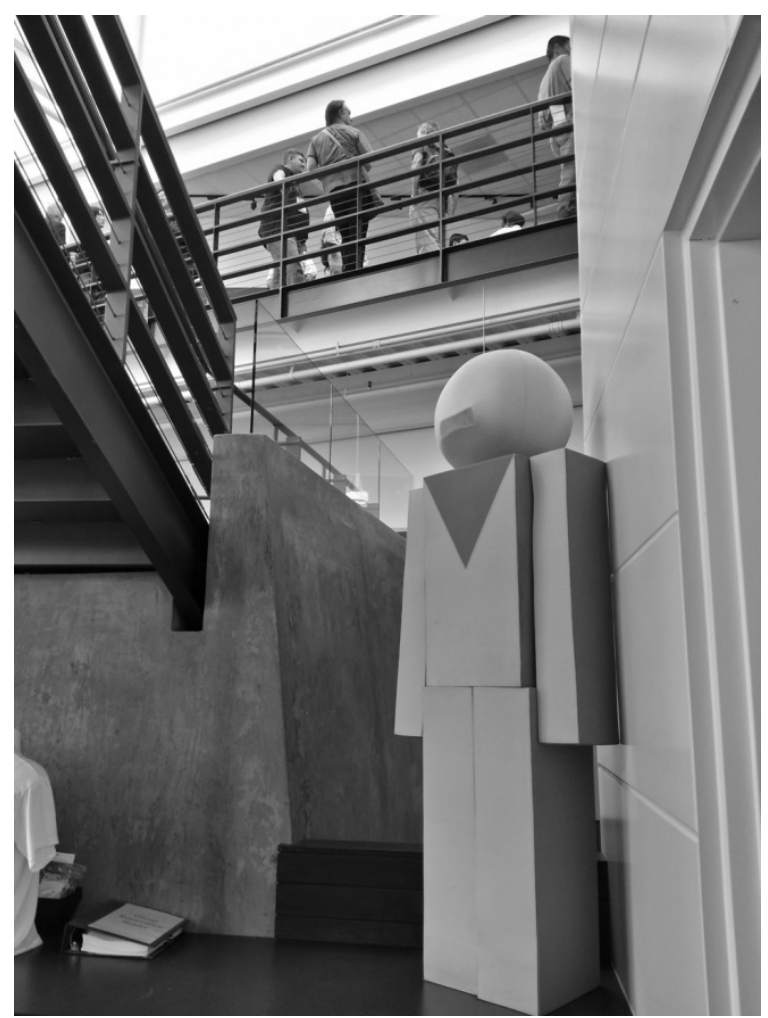

Fig. 1. A wearable costume of PegMan from Google Maps with Street View stands guard over the front desk

1 Revolution: The First 2000 Years of Computing," Web version. The Computer History Museum, 2011. http: / /www. computerhistory.org/revolution 
and Google Maps with Street View ${ }^{2}$, and with our current project, an upcoming exhibit on game-changing software ${ }^{3}$ that will include in-depth case studies of Wikipedia, SMS text messaging, World of Warcraft, and iTunes. I'm the curator for all but the latter two.

We hope that by sharing these challenges and the solutions we chose, we may contribute to an exchange of ideas. A critical-long term goal of our Internet History Program is to make the history of the online world more accessible and useful, both to the public and to decision makers - who can draw from the lessons of its past in determining its future.

\section{Exhibiting the Immaterial}

The online world that increasingly absorbs our time and energy, fills the business pages of now-online newspapers, and makes or breaks regional economies is quite

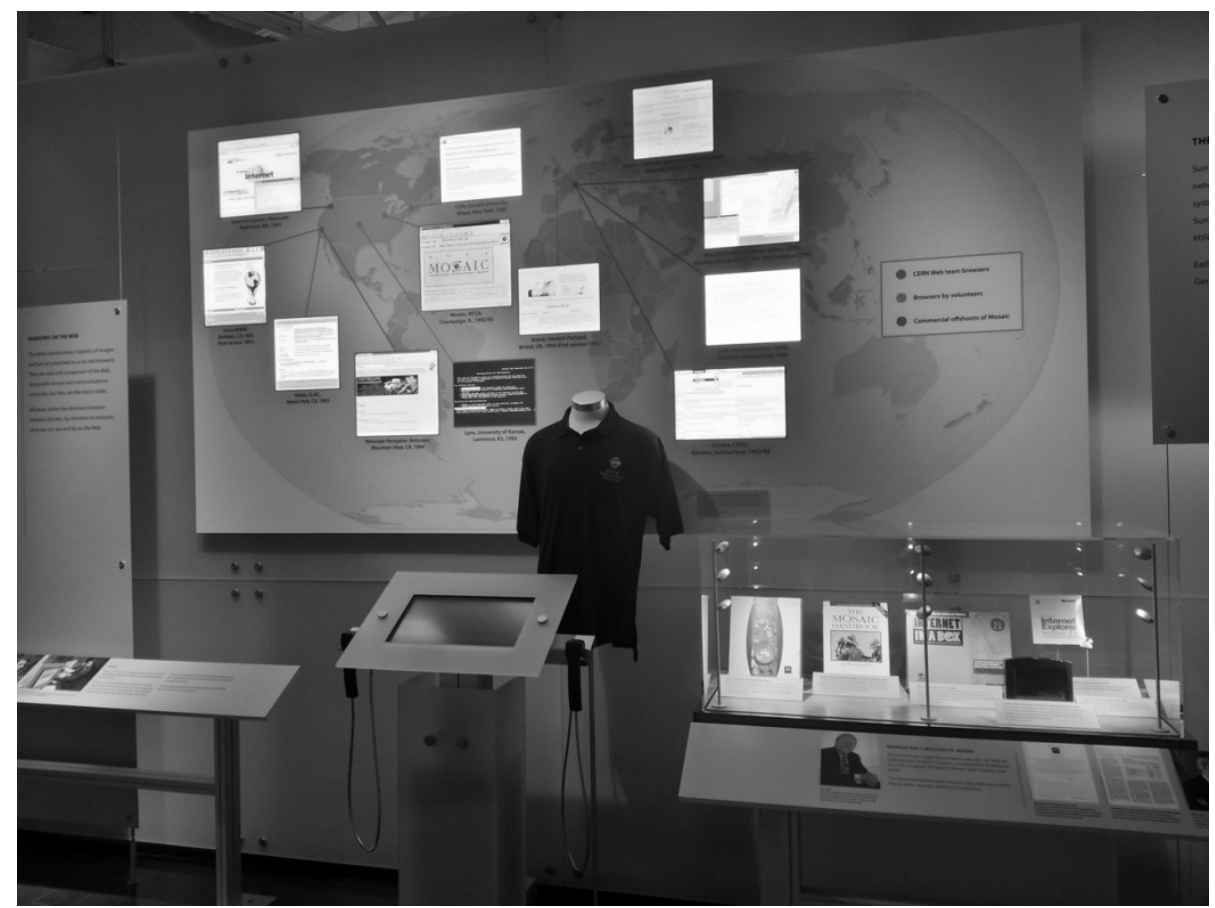

Fig. 2. In the panel above the lighted screenshots are the dominant visual, with artifacts and text below as support

2 "Going Places: A History of Google Maps with Street View." @CHM blog, the Computer History Museum, 2012. http://www.computerhistory.org/atchm/goingplaces-a-history-of-google-maps-with-street-view

3 "Make Software, Change the World!" @CHM blog, the Computer History Museum, 2012. http: / /www. computerhistory.org/atchm/make-software-changethe-world/ 
insubstantial. If an observer from the past were to land in our time, he or she would be struck by how many people were staring into glowing, flickering, ever-changing rectangles. Some of the rectangles are hand-sized, like your smartphone. Others sit on desks or stands. The biggest cover walls. In the future, personal ones may be constantly suspended on the edge of our vision in heads-up displays like Google Glass. The Onion satirized this modern reality with "Report: 90\% Of Waking Hours Spent Staring At Glowing Rectangles."4

An obvious technique for physical exhibits, then, is to pin and display some of the fleeting images on those glowing rectangles onto yet more special rectangles within the gallery, in the form of screenshots. We do exactly that, as you can see in these pictures from the "Web" gallery of our permanent "Revolution" exhibition (Figs. 2 and 3 ).

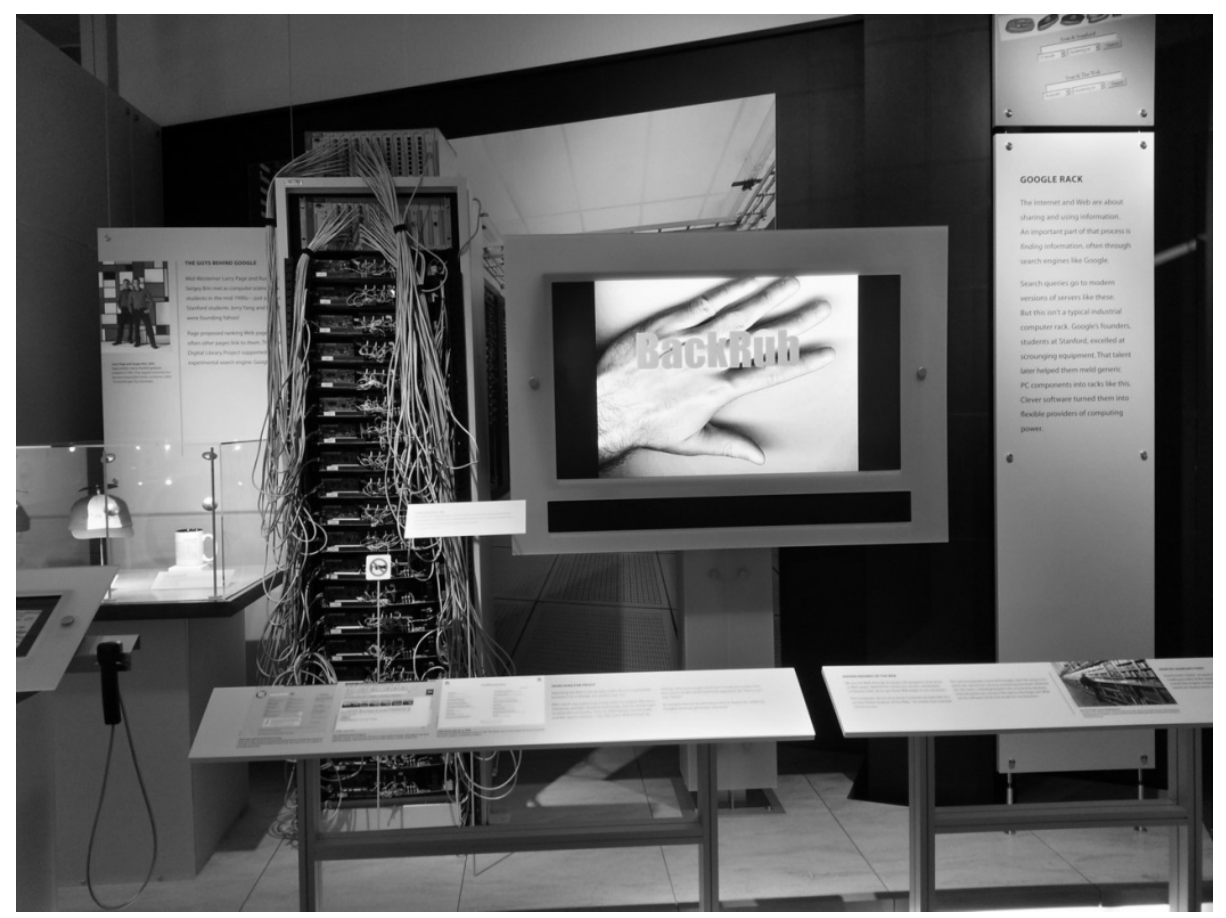

Fig. 3. Another example of a screen as the dominant visual. The image on the screen is the original logo for what became Google, called "BackRub." That's Larry Page's hand.

4 "Report: $90 \%$ Of Waking Hours Spent Staring At Glowing Rectangles." The Onion, 2009. 15 June 2009. http: / / www . theonion. com/articles / report-90of-waking-hours-spent-staring-at-glowing, 2747 / 
The Museum's VP of Collections and Exhibitions, Kirsten Tashev, intentionally took this a step further when she reversed the usual order of exhibits and put the screenshots up high as the star attractions, with a few intriguing objects in cases below to add texture. With the vivid lighted images and jewel-like detail of the objects, it is a powerful, sometimes beautiful technique.

But of course the online world is not just static images. It is more like an ongoing conversation, or a literature; an interactive experience that unfolds over months and years of practice and immersion. How can a visitor break into such an extended conversation in just a few minutes?

An obvious answer is to provide re-creations of the live online system itself. Simply let the visitor login to Minitel, the French online system that was a 1980s dress rehearsal for the Web, or browse early Web sites on original browsers, or surf the rich online discussions on the PLATO educational system. After all, the four playable games in our "Games" gallery - Pong, Adventure, PacMan, and Spacewar! are extremely popular interactives (Figure 4).

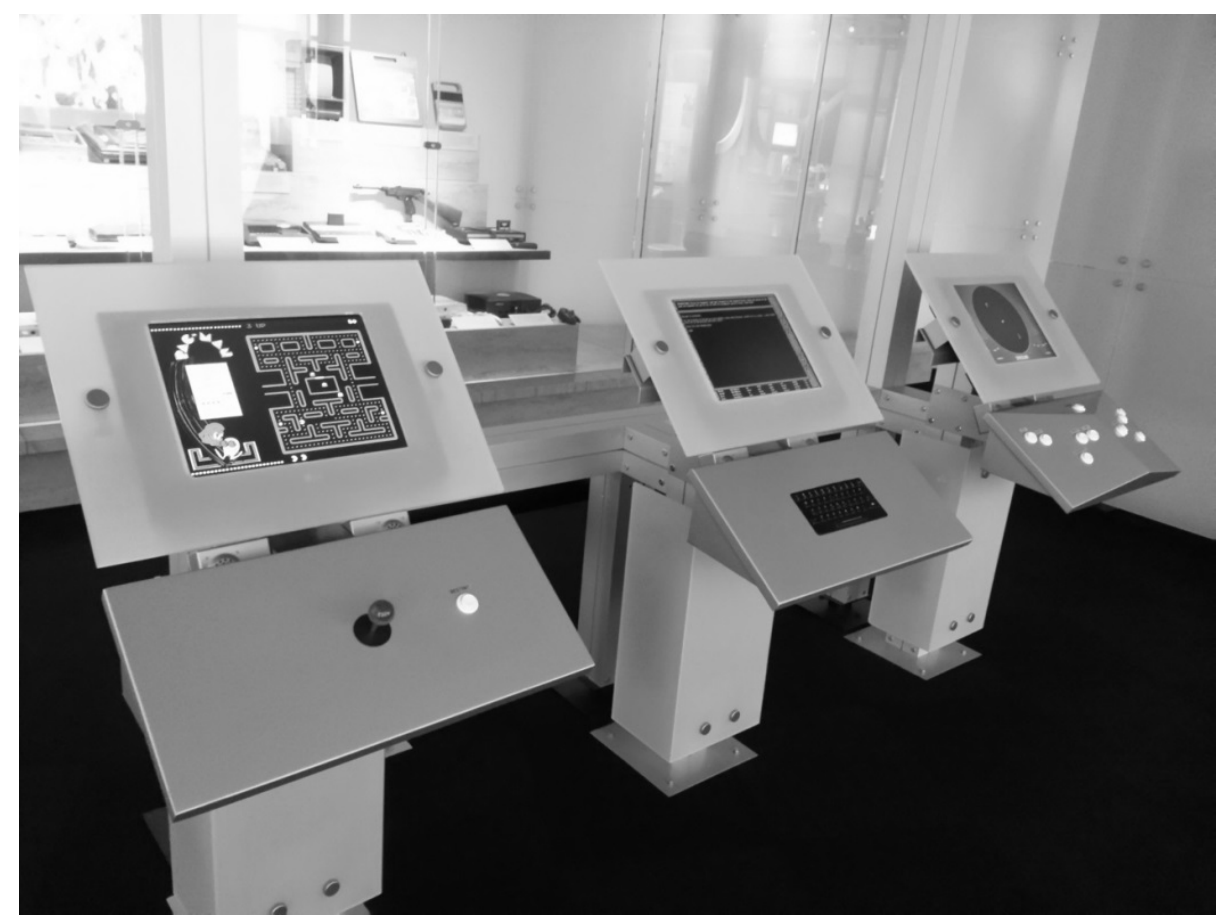

Fig. 4. These playable games from the 1960 s, '70s, and ' 80 s are a popular interactive

Alas, it's not always so straightforward when it comes to complex online systems, whether Gopher or Minitel. Even if the original software exists and can be run reliably, there's a big potential obstacle: Learning! Games are literally designed to be fun. They're also designed to be quick and easy to get started, however hard to master. 
Online systems are different. You may remember your early ventures into cyberspace through the glow of nostalgia. Or perhaps with mild disdain for what now seems like rudimentary technology. But either way, it's easy to forget the hours and the false steps it took your newbie self to get comfortable on the Web, or CompuServe, or whatever.

Three years ago the Museum helped host a spectacular multi-day commemoration of the $50^{\text {th }}$ anniversary of the PLATO online system. As part of it the people at the PLATO History Foundation lovingly assembled a collection of PLATO terminals from several eras, connected to a working re-enactment of the system. For original members of this close-knit community it was clearly an important, even moving experience to login once again to the familiar orange screens. But I noticed that my feet weren't pulling me toward the re-enactment area where the terminals sat in front of low, comfortable chairs.

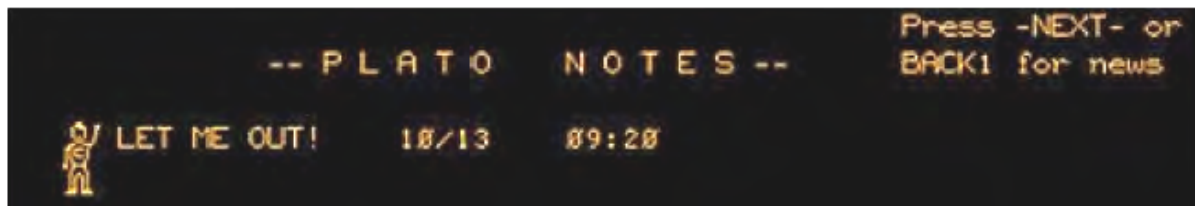

CHOOSE AN OPTION \&

a. Read about NEW SYSTEM FEATURES

b. Read \& write PUBLIC NOTES

c. Read \& write other GROUP notes

$\rightarrow$ d. Read PERSONAL notes to you

D. Write PERSONAL notes to others

e. Report a broken terminal

Press HELP for information.

Fig. 5. PLATO Notes, email and discussion. Courtesy of Mike Capek 
I'd never used PLATO and I was curious to know what it looked and felt like. But I realized I wasn't looking forward to the actual experience of getting started. It felt like work, like a tutorial in an unfamiliar piece of software, which is precisely what it was. It seemed like the kind of task to do at home or at my desk rather than in the middle of a conference. Now there were pioneers to meet, pictures to take, tasks waiting in my inbox. I eventually pushed myself, and spent quite a while playing with PLATO Notes and various educational modules. It was easy to use, and just as innovative as the old-timers said, and I'm glad I did it. But I've been studying the online world for nearly two decades. If a Web historian has to push himself to play with a historic system at an event, how much interest can you count on from the average casual museum visitor, pressed for time on a gallery floor?

It is also hard to say whether my session of mostly poking around and figuring out the lay of the land gave me any real sense of what an experienced PLATO user would actually do online. I imagine he or she would be more likely to jump straight into a rich conversation thread, for example, than spend time trying to figure out the commands that make PLATO Notes work. It can sometimes be more useful to look over the shoulder of an experienced guide than try to improvise a self-guided tour. Why not video where the expert goes, like a dashboard camera in cyberspace?

That's what we did in the Web gallery of "Revolution", where visitors can watch Web pioneer Kevin Hughes demo and explain a variety of key sites in "Surfing the Web in the Early 1990s" (Figure 6). It's also how we show the pioneering 1978 Aspen Movie Map in our temporary exhibit on the history of "surrogate travel" and Google Maps with Street View.

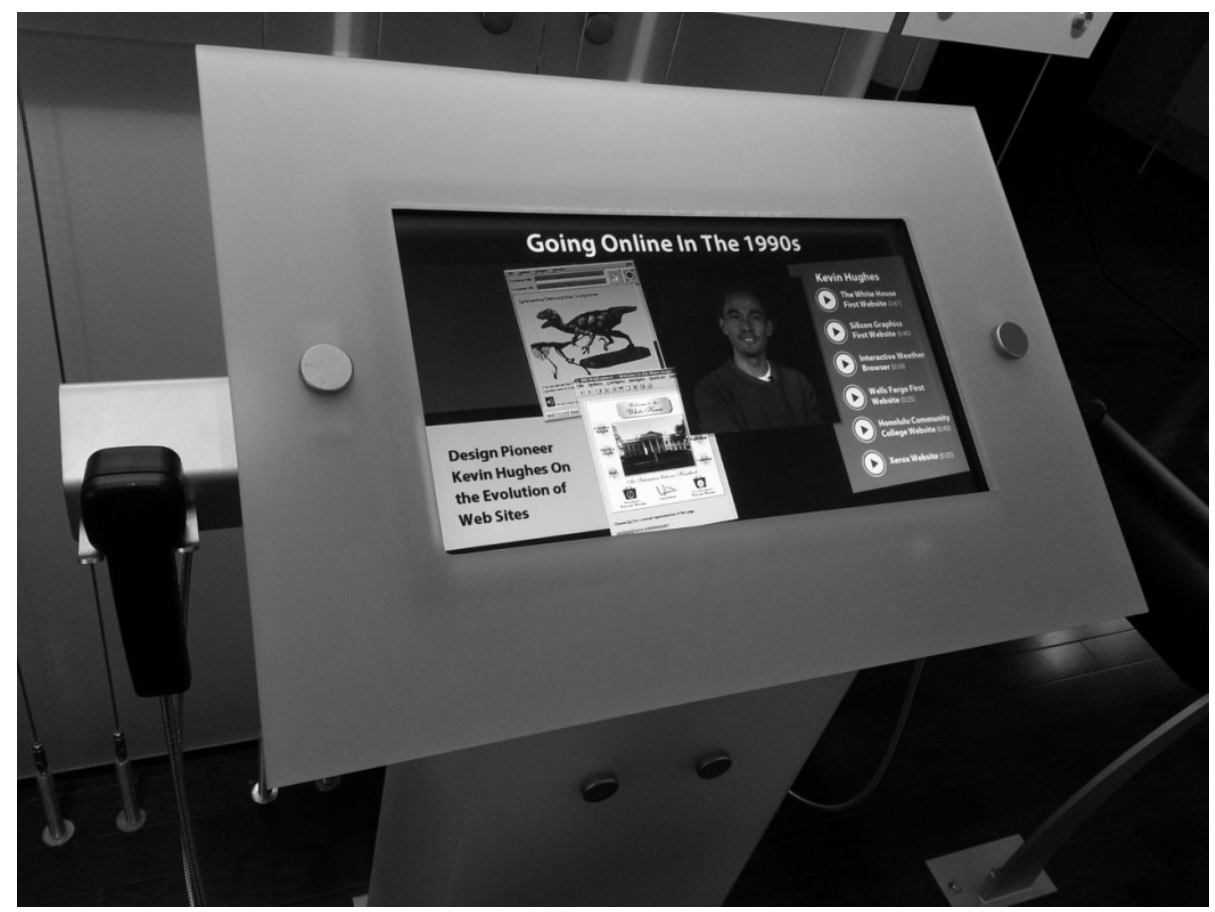

Fig. 6. At this personal video station, Web and graphics pioneer Kevin Hughes takes visitors on a guided tour of key early Web sites 
A common rule of thumb with museum interactives is that they have less than 30 seconds to "hook" the visitor with some rewarding experience before the visitor loses interest, and if the hook works, perhaps another three to four minutes for the whole interaction. When it comes to raw, live content, many video games can and do make the cut. Surfing simple and appealing historic Web sites should also work well - at least as long as Web-surfing remains a familiar act for most visitors!

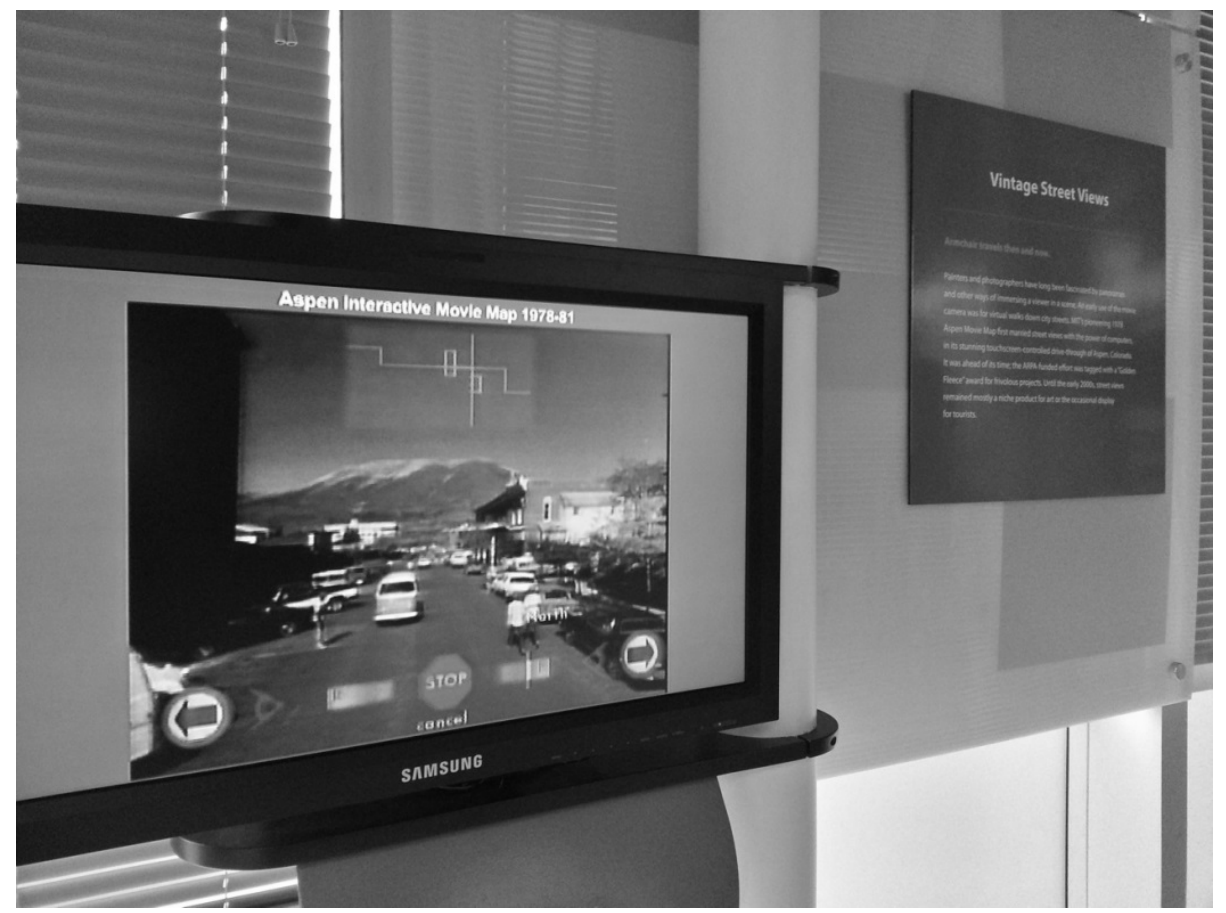

Fig. 7. This original early 1980s videotape shows a narrated demo of the pioneering Aspen Movie Map, which offered many of the features of Google Maps with Street View

But just as in the physical world, when it comes to more complex online tasks or environments visitors often benefit from a guided tour. These can range from simple video clips of online systems (Figure 7), narrated or not, up to various kinds of structured interactives. For instance, our upcoming Wikipedia exhibit may include an interactive that guides visitors through the basic process of editing Wiki articles. The structured portion of our Google Earth interactive let's users choose guided tours of historic Silicon Valley sites from the Hewlett-Packard garage to Netscape (Figure 8). But once at those sites, they are free to browse independently.

The rules change for the Web version of exhibits. Here the visitor is often comfortably seated somewhere quiet, rather than slogging through a gallery with finite energy and time. As we discover stable, permanent emulations of past online 
systems we hope to link to them from the Web version of "Revolution," 5 which includes all the content in the physical exhibition plus more. In my view, online is the right place to freely explore ancient online environments. This is where interested visitors, researchers, and students may truly get to know the many "webs" that came before the Web at their own pace.

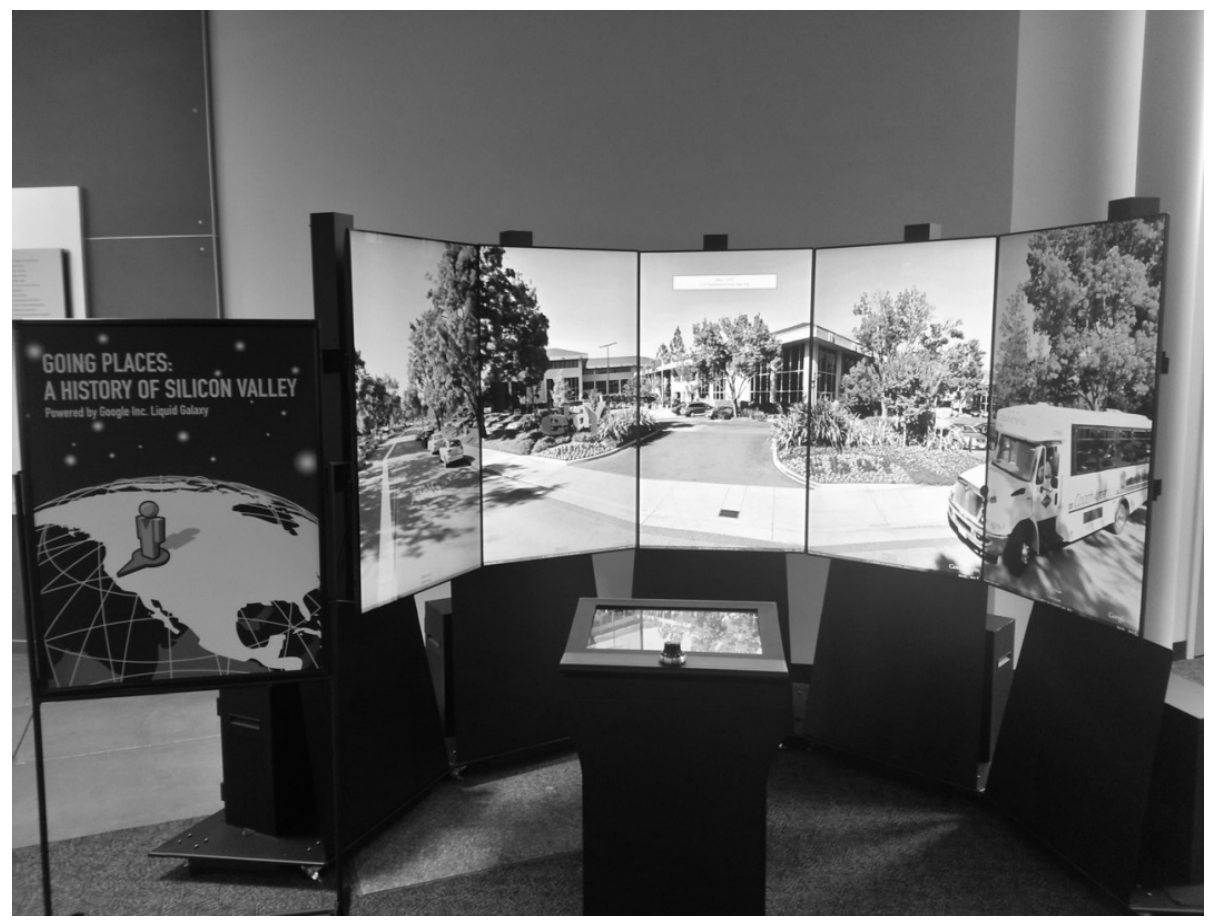

Fig. 8. This giant Google Earth station lets visitors take a guided tour of Silicon Valley, or explore Earth, Mars, and the Moon on their own

Of course, only a few historic online systems are available in emulated form. Of those that still exist at all, a number require original hardware, which has its own issues; old computer equipment is mostly fragile, sometimes rare, and requires ongoing investments of time and money for maintenance and training. The result is that such setups are easiest to use occasionally or intermittently. Examples include special events, such as the PLATO commemoration, and scheduled demonstrations.

For instance, the Museum does scheduled demos of restored or historic machines including an early 1960s DEC minicomputer (where visitors can play the first shootem-up game against its creator), a medium-sized 1960s IBM business computer, and a mechanical Babbage Difference Engine. The PC "Explainer Stations" in development will give visitors hands-on experience with classic Macs and IBM PCs with a docent available to assist. A very early Galaxy arcade game is on temporary exhibit and fully playable. Similar models could be extended to classic online systems.

5 "Revolution: The First 2000 Years of Computing," Web version. The Computer History Museum, 2011. http: / / www. computerhistory.org/revolution 


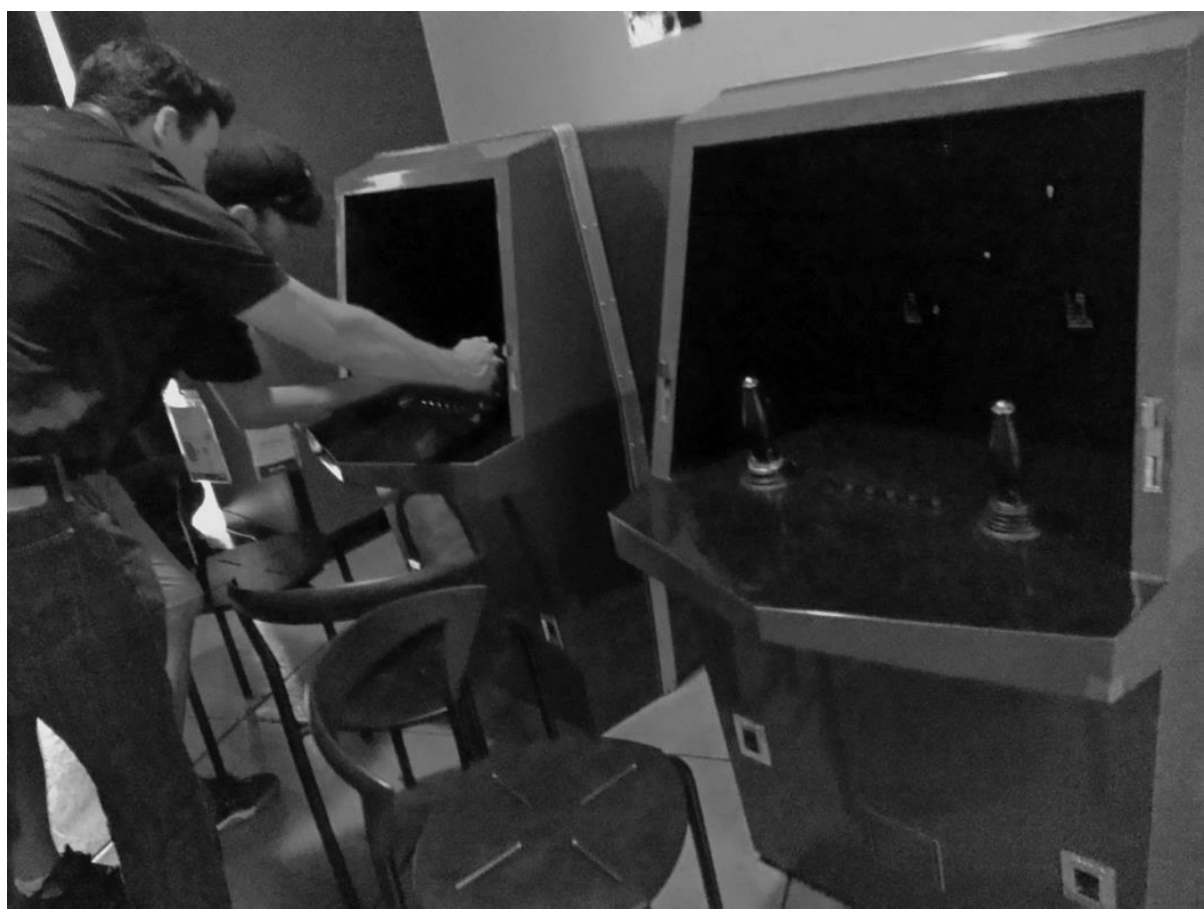

Fig. 9. These early 1970s Galaxy arcade game consoles are on temporary exhibit and fully playable

In general, one of the biggest obstacle to direct re-creations of online systems is social interaction. A standalone early Web site or 1980s Minitel site is still quite meaningful without other live users. But a 1980s CompuServe chat room, a virtual world from the 1970s on, or a modern Twitter feed is far less so. To re-create such systems is like trying to freeze and reproduce the back and forth of a live, group conversation.

For highly social online systems like virtual worlds, some researchers have essentially had to give up on trying to meaningfully preserve the system itself. For them, video has become a standard way to capture the look and feel of the online experience not just for exhibits, but for preservation purposes. As the Web returns to the more social models and user-generated content that marked many early systems, the preservation of ordinary Web sites may face similar issues.

\section{Audience Appeal}

Objects vary a great deal in their natural "exhibitability," to use an awkward-sounding term. The spectrum can resemble Maslow's hierarchy of needs ${ }^{6}$ in reverse, running from the personal and visual down to the dry and abstract. At the top might be

6 Maslow, A.H. (1943). A theory of human motivation. Psychological Review, 50(4), 370-96. 
paintings and sculpture, since like most art they are purposely made to be interesting. High up, too, are small personal objects, jewelry and watches and such. Such items are carefully designed and easy for a visitor to "read." Their use is usually clear, as is their connection with the lives of their one-time owners.

Objects linked to taboo subjects like sex and violence score high, of course, from flint daggers to lingerie. Then there's nearly anything connected with vehicles, old or new, which perpetually fascinate, and all manner of machines with shiny moving parts. Then come the rest, wending their way down to things like ordinary documents and the sorts of anonymous enclosures that house much "back end" computer equipment.

\section{Maslow's Hierarchy of Human Needs Physical to abstract}

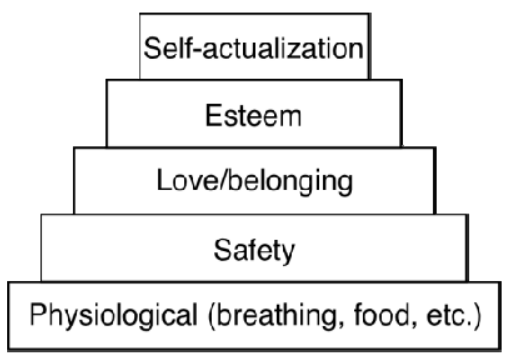

Exhibitability Appealing to dry

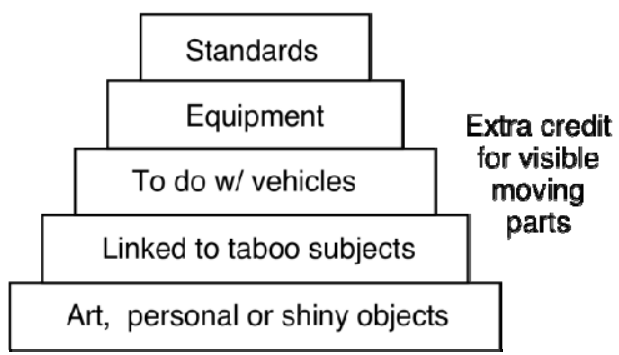

Fig. 10. Hierarchy of "exhibitability," at right

A number of computers and peripherals themselves can push one or another of the hot buttons above, from those in vehicles (Lunar Lander computer), to weapons (fire control computers), to clothing (wearable computing), and more. Some manage to tick multiple boxes, like the guidance computers for intercontinental ballistic missiles.

As we move closer to the online world, the easy pickings get scarcer. But there's still one relatively rich vein of "exhibitability": mobile computing, whose later history veers almost completely online. The little computers are a relative snap to display, since they're small and intimate enough to get much of the same design treatment, and human connection, as other poignant personal objects. Though in one sense they are just more life support systems for "glowing rectangles", mobile computers are far more different from each other - and thus intriguing - than their full-sized desktop cousins.

But the problem of how to show off their little rectangles remains. The thorniest question with the Mobile Computing gallery in "Revolution" was whether and how to show the actual contents of the screens, the software that makes them go. No option is perfect. To not show the screens at all would be like showing half of the device, especially with smartphones and handhelds where the software is often completely integrated. Trying to mock up the screen in place would look fake, the way smartphones are displayed today at stores that lack the budget for live demo models. The compromise we settled on is to show screenshots in a rotating picture frame positioned behind a cluster of machines. When we can find contemporary ads that clearly show the screen, we use those. 


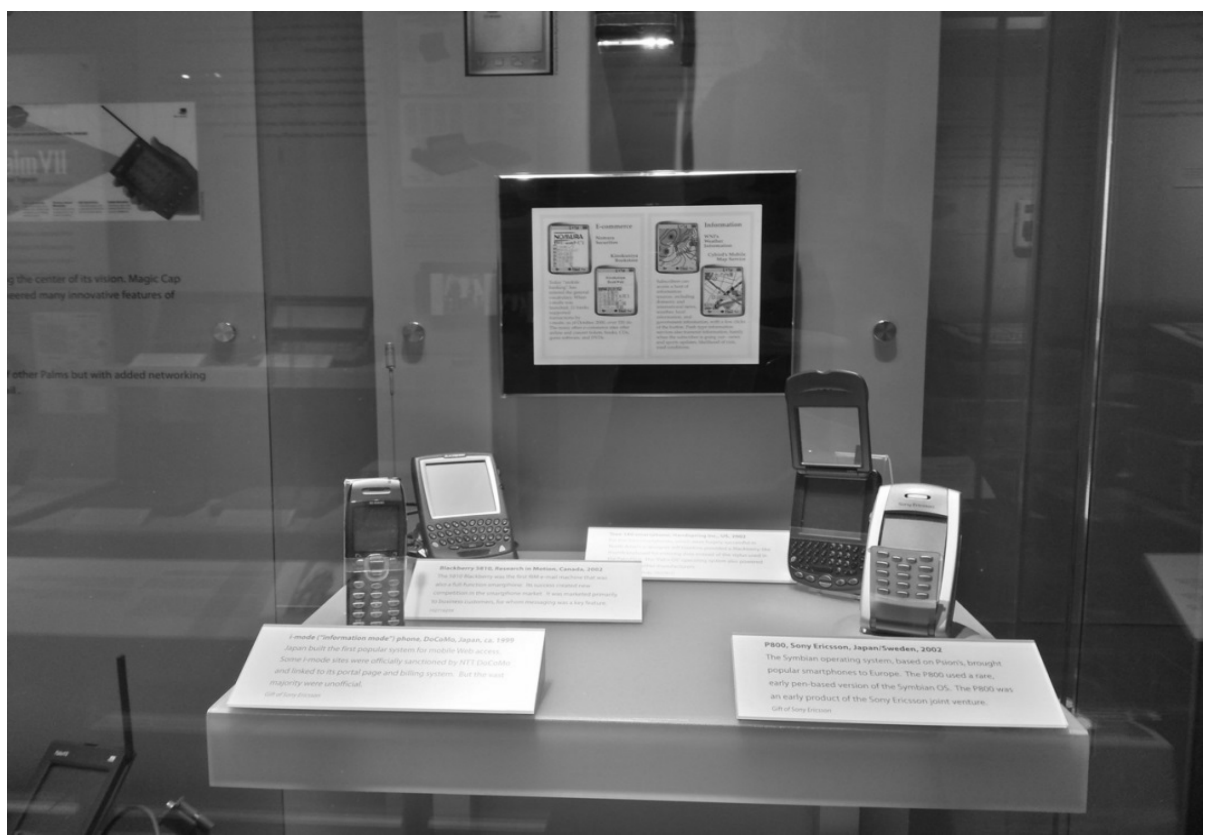

Fig. 11. In the section shown above, screenshots of the software from the physical objects on display is shown on the video screens

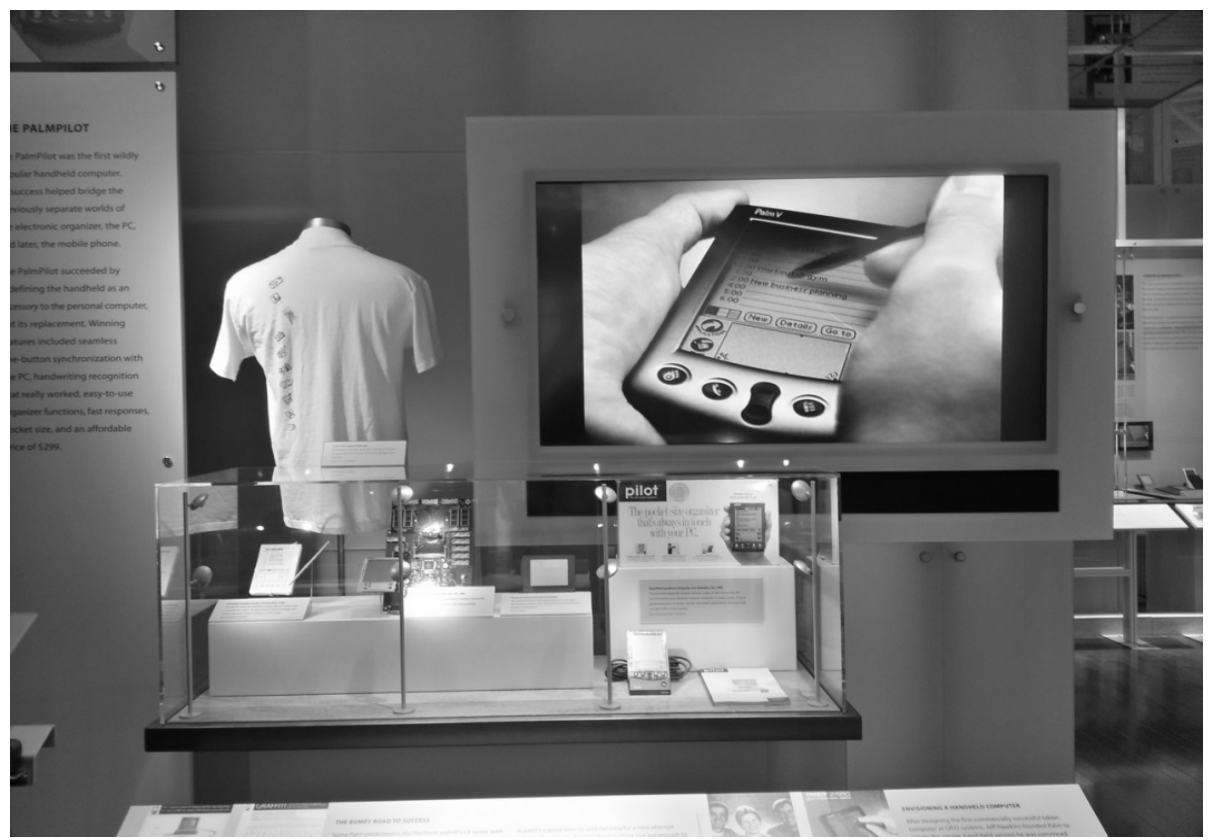

Fig. 12. A related example, where the large screen handles the task of showing the Palm software in action, through old TV advertisements as well as static screenshots 


\section{$4 \quad$ Exhibiting the Invisible}

There is a final frontier, a place where the last crutch of easily exhibitable items gets kicked away. Behind the glowing screens that while away our hours lies an enormous infrastructure, one that runs out from our home Ethernet routers and spans the globe with wires, and server farms, and undersea cables, and satellites, and radio towers. The recent book Tubes by Andrew Blum ${ }^{7}$ explores this physical structure of the online world.

But even though there's so much physical stuff, millions of tons of equipment power-hungry enough to suck down over two percent of the world's total production of electricity, there's a big problem when it comes to putting it on display. Much of it looks the same, and has for decades. Even removing a front panel often just reveals standardized circuit boards and power supplies with few obvious differences to the layperson's eye. In fact, it can be hard to tell from just looking whether, say, a given set of featureless cabinets in a windowless back room are for computer networking or telephone systems.

So how do you exhibit these underpinnings of the online world, explain the origins of the "plumbing" layers like the Internet where bits get moved around - but there may not even be any friendly screens or human interface of any kind? In developing the "Networking" gallery of "Revolution," this was precisely the challenge.

You can see gears move on a steam engine, or a Babbage engine. Even the old electromechanical telephone switches are impressively intricate and physical. But you can't see electrons move over a network. The action, the variety, the magic that eventually brings our screens to life is all on the inside, invisible. Also barely visible are the marks of the bitter, decades-long standards wars that form much of the history of networking.

Had ARCNET won the battle to wire the office instead of Ethernet, the only obvious difference might be a slightly different shape of connector to plug into the back of your machine. Had the French CYCLADES network become the standard for connecting networks to each other, instead of the now-familiar Internet protocols, there might be no physically visible difference at all. The equipment could look just the same. But the economics of the online world, the balance of power over standards, and in some cases what you can and cannot do on your glowing screens would be quite different.

So what do we do in the "Networking" gallery? Of course we show particularly meaningful or representative examples of the sorts of often "faceless" behind-thescenes equipment that makes the online world run: a refrigerator-sized hardened IMP from the original ARPAnet; a Cisco router; a dish antenna; a Google server rack, and so on. But one or two of each major class of equipment is usually enough.

7 Blum, Andrew. Tubes: A Journey to the Center of the Internet. Ecco, 2012. 


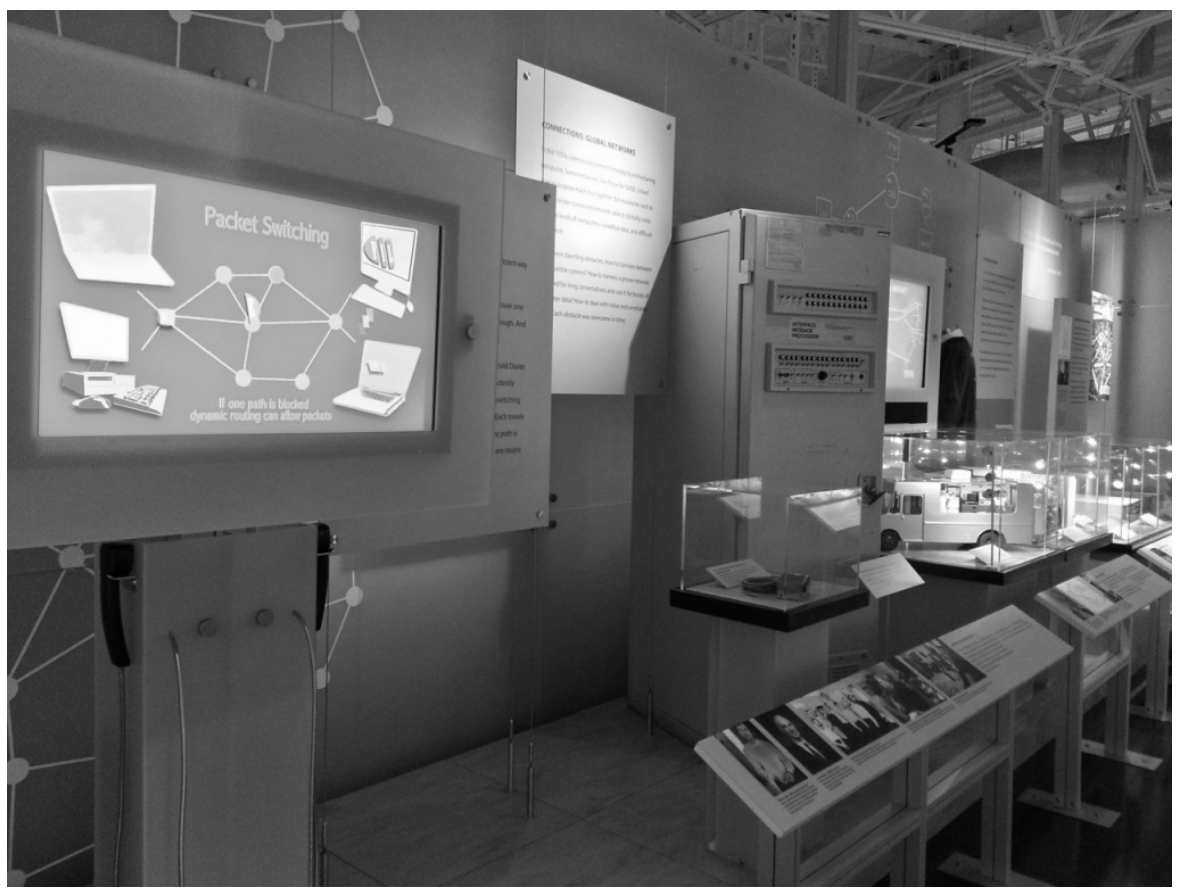

Fig. 13. A portion of the "Networking" gallery in "Revolution." An animated video explaining packet switching is in the foreground. A refrigerator-sized IMP (Interface Message Processor) from the ARPANET, which led to the Internet, is behind.

Beyond that, exhibiting a networking design like packet switching or a standard like Ethernet is rather like displaying the wind. Invisible itself, it can still be seen by its effects. This is where you enter the same rarified realm as exhibits on other abstract topics, from math to the hard sciences, or on processes like cellular respiration. The solution is to sharply outline the impact of the law, or concept, or other insubstantial thing on the tangible world around it. You show its effect through people, objects, interactives, and other things that $d o$ have a clear exhibitability - and become a kind of bait. It's like boldly outlining the visible arc of grass and trees as they bow to the unseen wind.

When creating an exhibit you have the luxury of hindsight. So those visible effects don't necessarily have to follow chronology. For instance, we start the "Networking" gallery with a common grounding theme throughout the exhibition; tracing the old roots of the subject to be explored. Here this takes the form of an interactive telegraph key. Visitors can tap out their initials, and feel under their fingers the staccato manifestation of the 200 year old "big idea" that underpins nearly everything in the gallery and the Museum: Transporting information over electrified wires. Over the centuries the wires have shrunk too small to see, and the switches have gone from something that filled your hand to millions per square inch. But the principle is the same, from Morse keys to ENIAC to the iPhone. 


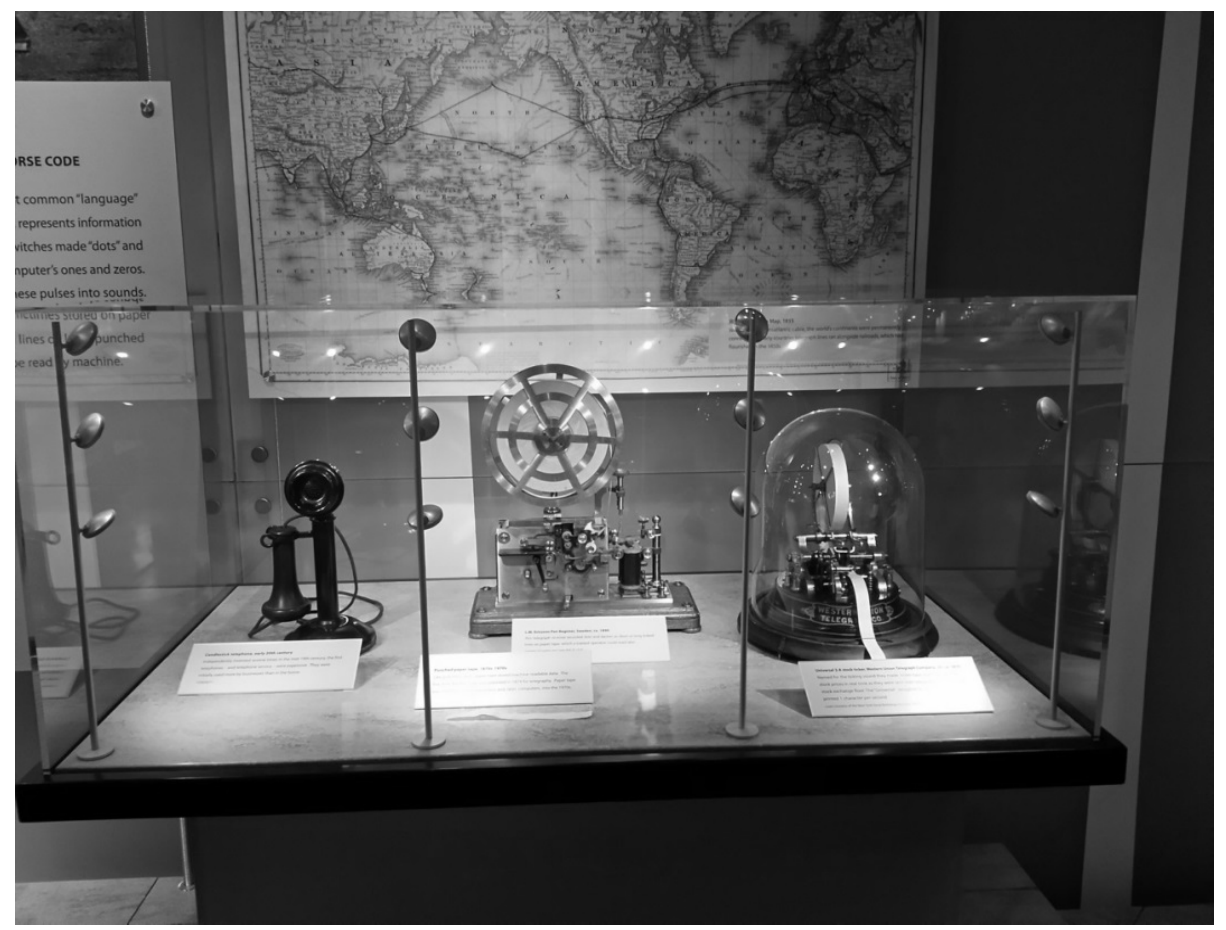

Fig. 14. Photogenic $19^{\text {th }}$ century telecommunications equipment

The gallery briefly luxuriates in the gorgeous polished brass and delicate visible gears of the ultra "exhibitable" equipment from the first wired world, that of $19^{\text {th }}$ century telecommunication. It shows early modems and a teletype. But then it tells the rest of the story with an increasing palette of indirect techniques. The principles of packet switching get covered in an animated movie. Pictures and stories about people - from the colorful networking and personal computing legend Bob Taylor, to Al Gore - literally flesh out the conflicts and ideas that drove the effort to tie computers together into a world-spanning net. Internet protocols get represented by a lovely scale model of the research van where they were first fully tested; The real van is in the Museum's collection. Books, t-shirts, and reprints of newspaper articles come in to illustrate particular points. A variety of network connectors show some of the few visible manifestations of the bitter and costly standards wars that raged through the 1970 s and '80s.

More than half of the stories in our upcoming exhibit on game-changing software are about the online world. They will draw on and extend the full palette of techniques we've used to tell online stories in "Revolution." But the structure of this exhibit, "Make Software, Change the World," highlights another technique in itself: the case study. By going in-depth with real-world examples, from Wikipedia to iTunes to World of Warcraft, the exhibit will anchor the sometimes insubstantial tendrils of cyberspace with specific people, and places, and uses. 


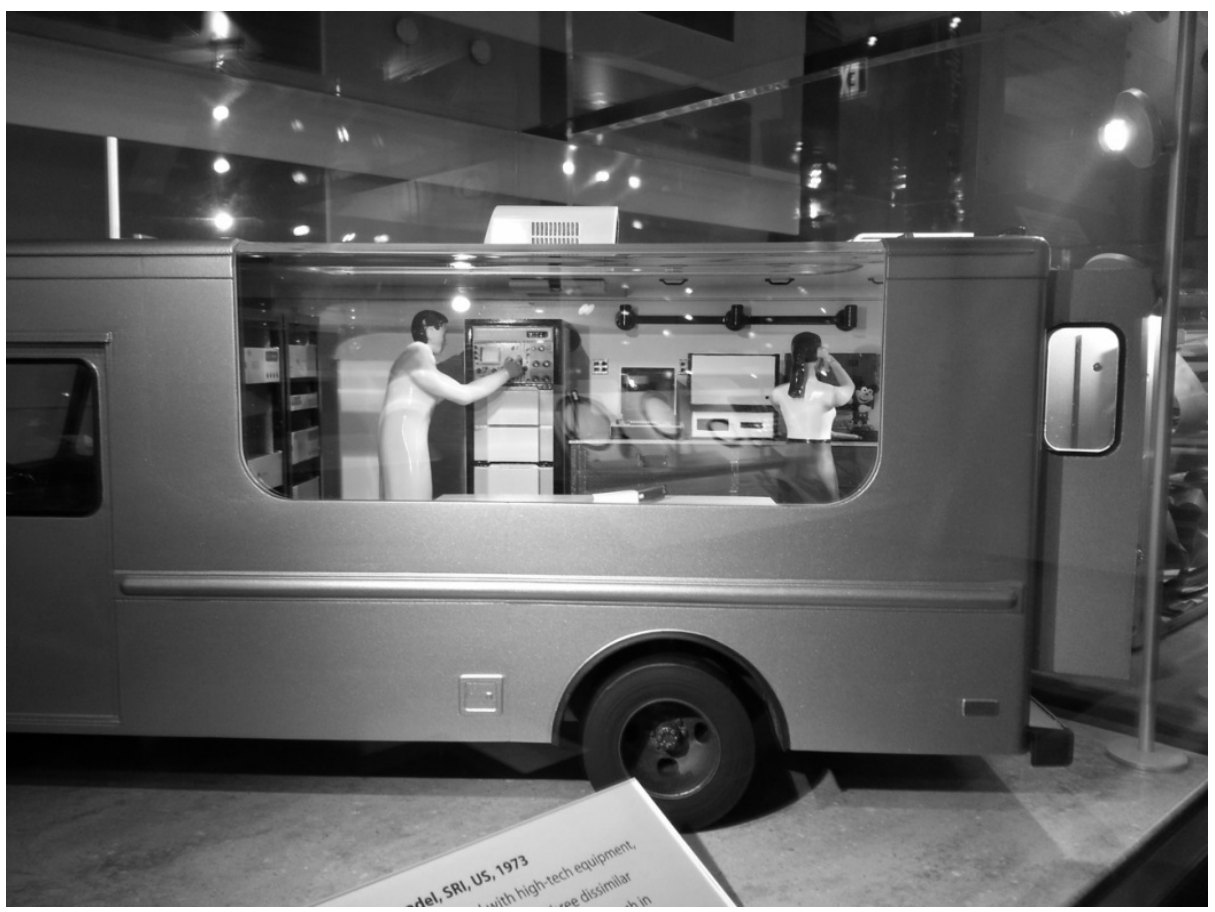

Fig. 15. Scale model of the SRI packet radio van, where the Internet, mobile data networks, and voice over IP (think Skype) were prototyped

\section{Between Telecommunications, Literature, and Computers}

Computers started as calculating machines made from spare parts of the then-centuryold telecommunications industry. They were later converted into communications and knowledge devices. A century from now, they may be seen as part of a larger stream of the history of technology for dealing with information. But today they still straddle worlds. This creates tensions when it comes to practical exhibits. Is the online world part of computing, or of the history of books and sharing information, or of telecommunication? All solutions are compromises.

The online world doesn't appear out of thin air. Its glowing rectangles are attached to computers, and those computers to networking equipment. But how much to exhibit these physical "support systems" for cyberspace within an exhibit on the online world can depend on context. Is the online exhibit standalone, or is it part of a bigger exhibit on computers, or communications, or something else?

As I've mentioned, much networking equipment is short on exhibitability. Computers themselves, though, can push some hot buttons. Yet the stories that make these computers interesting often have little to do with any online roles. For instance, the story of early Apples is animated by the rivalry between Jobs and Gates and the funkily home-built nature of early PCs. The SAGE system was a milestone for networking with 23 centers connected in the 1950s. But it was equally important 


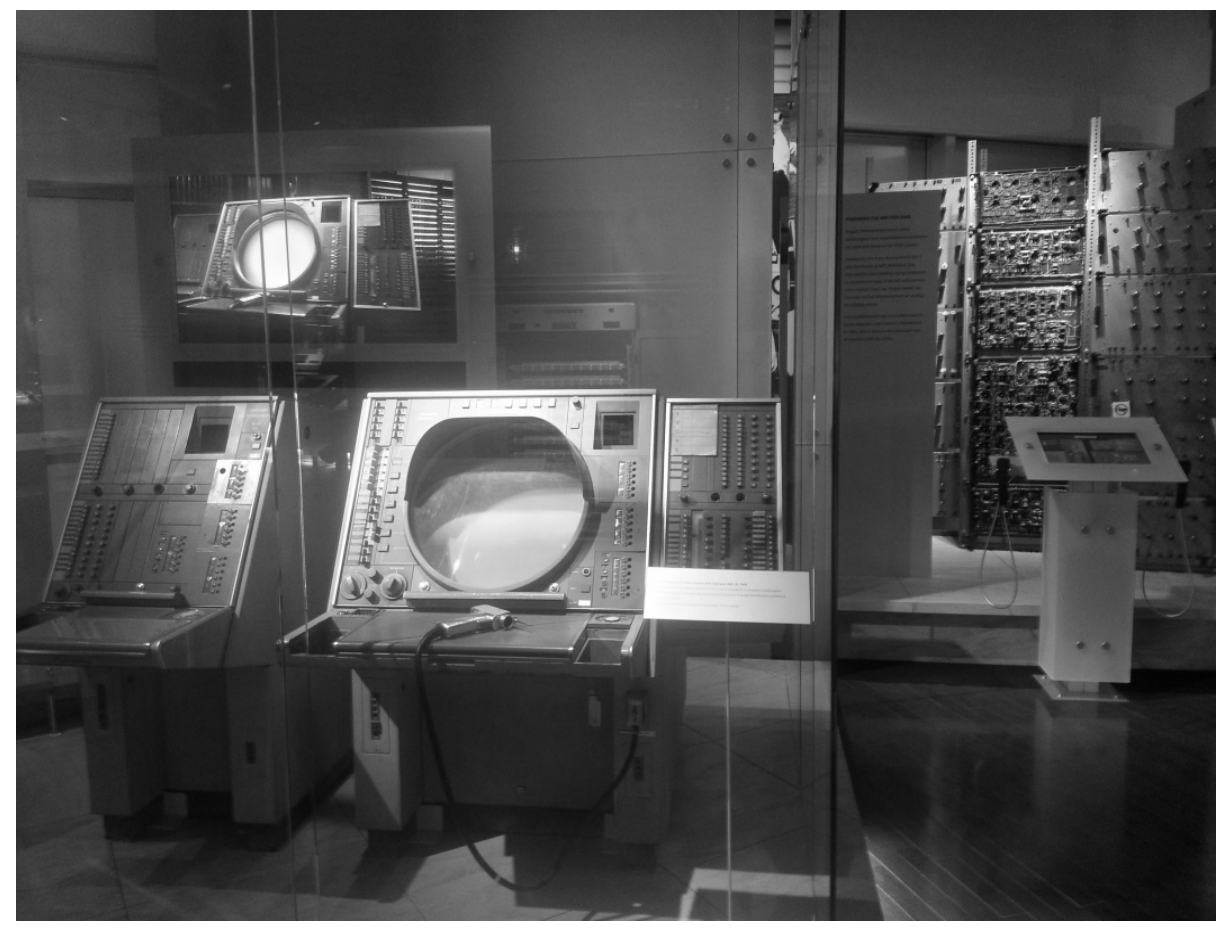

Fig. 16. Just a support system for going online? SAGE terminal, Real Time Computing gallery, "Revolution."

for interactive computing, and use of a pointing device, and military computing, and more. Using such computers in a pure cyberspace exhibit can potentially shortchange their other roles. But putting them in other galleries reduces the stock of interesting online objects.

We put SAGE in the "Real-Time Computing" gallery, and the Apples are with PCs. Both are referred to in Networking and the Web. But it's an imperfect compromise, especially in the physical exhibit where there's no convenient way to cross-link.

\section{$6 \quad$ Framing Complexity}

Historical common knowledge is dramatically uneven. Most people have some idea of where the airplane came from, or the printing press, or spaceflight. But only a very few can tell you much about the origins of television or broadcast radio. Unfortunately for exhibit purposes, the online world falls into one of these societal blind spots.

The fact that most people are quite ignorant about the real origins of the online world is a double-edged sword. It makes it easy to offer enticing revelations as "hooks"; for instance that the Web was originally meant to be as participatory as a giant Wikipedia, or that social networking features go back to the 1960s. But it also 
means that exhibits need huge amounts of backstory and framing context for each section, adding to both the size of any display and to potential information overload for visitors.

Both of these effects are intensified by another factor. While most visitors have no preconceptions at all about, say, the origins of analog computers or disk drives, the Web and Internet are so much a part of modern life that nearly everybody seems to recall a few bits and pieces about how they got started, often wrong.

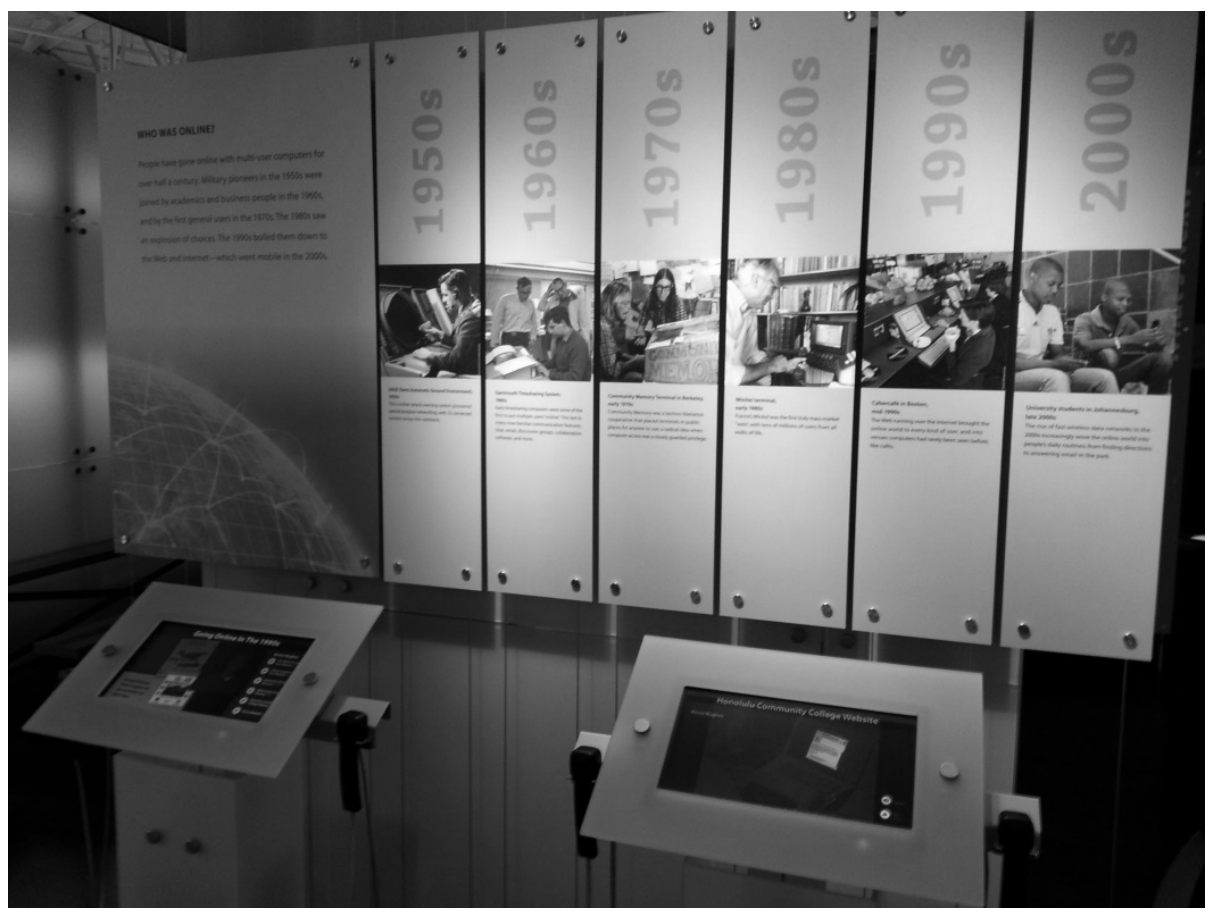

Fig. 17. "Who was online?" panel conceptually groups a number of disparate systems and explores who used them. Networking and the Web, "Revolution" exhibition.

\subsection{Paradigm-Shifting Facts}

Below are examples of key facts that stretch or challenge common knowledge, requiring a great deal of context and emphasis to get across. They thus presented both problems and opportunities when designing "Revolution."

\subsubsection{The Web Is not the Internet!}

The Web and Internet represent two completely different levels of the online world. They are as different from each other as TV sets from the shows that play on them, or programs from operating systems.

To many people, the Web and the Internet blend together in a kind of cyber mush; they have no idea where one starts and the other ends, and no practical reason to care. The fact that the Web is an online information system running over the basic 
"plumbing" provided by the underlying network - in this case the Internet - is extremely abstract to many visitors. But making this distinction is key to the narrative arc of the gallery, since each level has its own quite distinct history.

We went back and forth with possible solutions. Should we try to tell both stories in a single gallery - or have two completely separate galleries, "Networking" and "The Web"? Or compromise, and have two separate "tracks" within a single gallery?

In the end we used the two-track approach for the physical exhibition, where visitors turn left for networking ("Connecting Computers") and right for the Web ("Connecting People") and follow their chosen track along the wall. Local Area Networking like Ethernet is a semi-separate branch off of the main networking track. But we created two completely separate galleries for the Web version of the exhibition, partly because there's no clear online analog to separate but associated "tracks." Both the physical and online versions have an introductory panel called "What's the Difference Between the Web and the Internet?"

\subsubsection{No Immaculate Conception}

The Web and the Internet did not spring up out of nowhere. They each had predecessors and competitors, and are the survivors of fierce competitions for the system that would dominate their respective levels. The same is true of Ethernet in the realm of local networks.

Most visitors - including some computing professionals - have little idea that there were Web-like systems before the Web, or other ways of connecting computers (and computer networks) to each other than the Internet. Without this key fact, tracing the origins of cyberspace is a bit like trying to present the history of World War I to an audience that doesn't realize there was more than one side.

The cycle of invention, competition, and winnowing is a repeating theme in the history of computing and other technologies. Throughout the museum's exhibits we present not only the winning standard or company, but also explore at least a representative sampling of the losers and minor players. This structure makes immediate sense to visitors in areas where historic competition is well known, for instance "Personal Computers." But it requires more explanation for the galleries covering cyberspace.

In "Networking and the Web" and "Mobile Computing," we call out the centrality of competition in the panel text, titles, and graphics, and show at least one object to represent each major competitor. But to avoid overwhelming visitors with too many individual stories, we present the competitors as bundles. For instance, the section discussing Ethernet's fight with standards like ARCNET and Token Ring is called "Local Area Warfare". The section covering the Internet's surprise triumph over rival standards including OSI, SNA and PUP is titled "Protocol Wars"; the label for an image of $\mathrm{Al}$ Gore explains how his support helped the Internet beat far bigger rivals. A large lighted panel shows screenshots of a number of the Web's 1980s predecessors and competitors, titled "Walled Gardens," and the text emphasizes the "triumph of the underdog" nature of the Web's eventual victory. 


\subsubsection{It's Older Than You Think}

From e-commerce to chat to social networking and user-generated content, most of the features we use on the Web today were already being used by tens of millions in the '80s on earlier online systems. But those systems weren't connected to each other.

Many visitors don't realize that the Web had any predecessors at all, as discussed in item two above. But in fact, starting in the early 1960s it was pre-Web online systems that pioneered most of the features we think of as "modern." The catch is that most of these earlier systems were isolated "walled gardens", available only to certain kinds of users or in certain geographic regions. Online systems in the 1960s through the '80s were a great example of William Gibson's observation that: "The future is already here; it's just not very evenly distributed."

A major focus of the "Web" sub-gallery overall is showing the surprisingly early origins of familiar features. It opens with a clay tablet to illustrate the 4500 year old roots of cross-references, now familiar as the clickable hyperlink. The "e-Commerce" section traces its roots to $19^{\text {th }}$ century telegraph days. When it comes to specific aspects of online systems, say chat or virtual worlds, the gallery discusses or shows the pre-Web systems where they began.

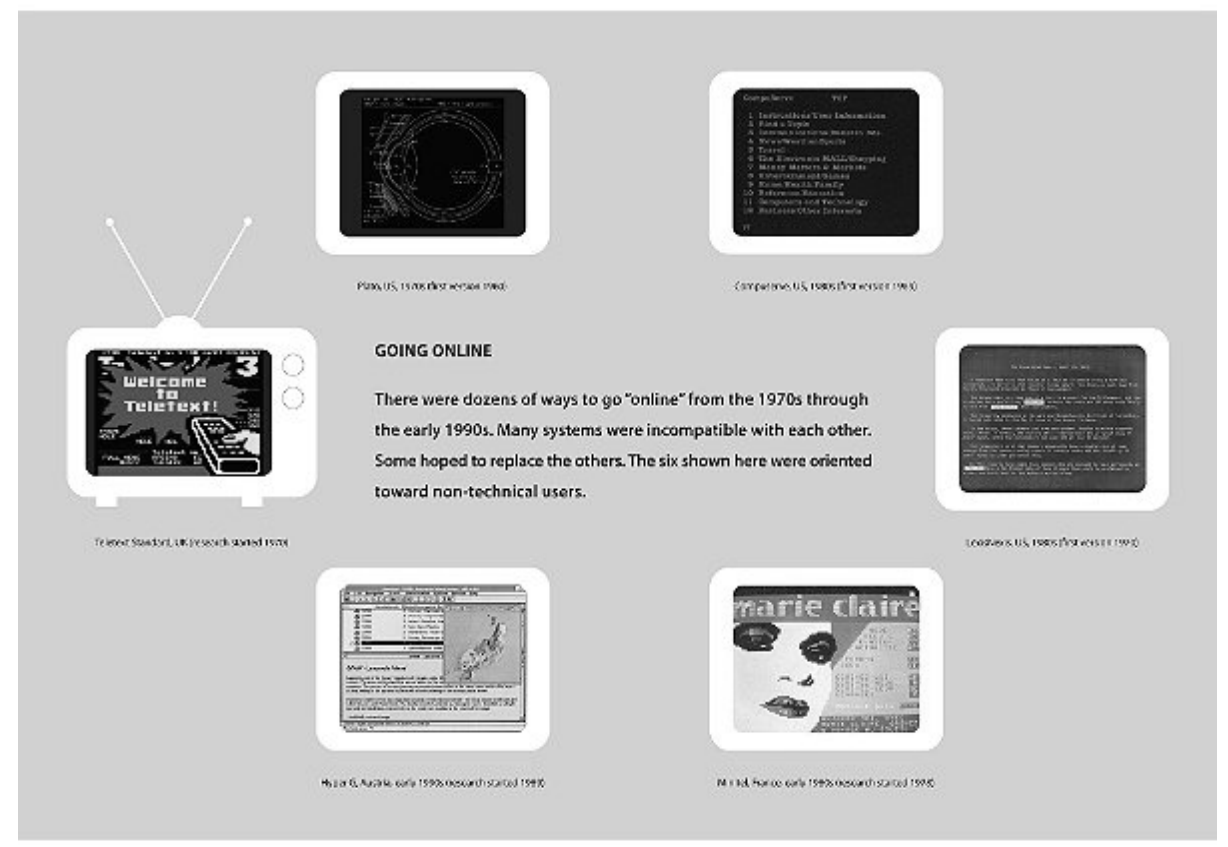

Fig. 18. "Walled Gardens" panel conceptually groups a number of 1970s and '80s online systems. Networking and the Web, "Revolution" exhibition. 


\subsection{Fun Facts}

But not all these "revelations" require heavy lifting. A number are easily digested, gee-whiz facts that can surprise and occasionally delight visitors. For instance:

- Social and collaborative features are some of the original uses of online systems; the Web is now catching up.

- The globe was wired by the 1870 s. The multinational communications industry was 100 years old when the digital computer was invented in the 1940s

- E-commerce, including spam, dates to the Victorian era

- Most early Web pioneers thought we would use directories, like Yahoo!, not search engines like Google

- Information overload is an old problem, and in the early $20^{\text {th }}$ century inspired several Web-like systems based on microfilm, telegraphy, early television, etc.

- The origins of the clickable hyperlink can be traced back to cross-references between clay tablets

\section{Conclusion}

Showing online systems in a museum context may be as paradoxical as music criticism or dancing about architecture, as I hinted with the quote at the start of this paper. But that doesn't prevent us from trying to do it well.

The palette of techniques described in this paper represent one set of solutions to the difficulties of representing the complex, immaterial, and dynamic online world in a static gallery. We can bring the look and feel of cyberspace into that gallery with dramatic screenshots, video snippets of forays online, structured interactives, and live emulations of some simpler online environments.

When it comes to networking standards and other unseen underpinnings of cyberspace that lack a human interface, we can address the scarcity of naturally "exhibitable" objects by emphasizing related items that are more so, from iconic hardware to portraits of the personalities involved. These indirect techniques are similar to those used in other kinds of museum exhibits that deal with abstract concepts.

The huge gap between common knowledge about the origins of cyberspace and the reality is both a problem and an opportunity. The sheer amount of background information required could be overwhelming to visitors. But by choosing simple but powerful themes, like competition, and then emphasizing them repeatedly where appropriate, we can bundle a large number of separate stories into manageable frames. If this framing is done properly, the "revelations" that follow can be a fun rather than disorienting, and an important part of the visitor experience.

A problem that no single gallery or exhibit can address is the societal "blind spot" about the very existence, and importance, of the long and rich history that produced the online world. Only time, and continued efforts to both popularize that history and to integrate it into relevant academic disciplines from Internet Studies, to Computer Science, to Sociology can gradually change the common knowledge and assumptions with which visitors approach the subject. 
Acknowledgements. The author thanks Kirsten Tashev, Dag Spicer, Alex Bochannek, and Emily Routman for help and advice in the preparation of this paper, and especially for all I've learned from creating exhibits together. I also thank Lynette Webb and Google for sponsoring travel to present the paper in person at the "Making the History of Computing Relevant" conference in London in June of this year.

\section{References}

1. Revolution: The First 2000 Years of Computing, Web version. The Computer History Museum (2011), http: / / www. computerhistory.org/revolution

2. Going Places: A History of Google Maps with Street View. @CHM blog, the Computer History Museum (2012), http://www.computerhistory.org/atchm/goingplaces-a-history-of-google-maps-with-street-view

3. Make Software, Change the World! @CHM blog, the Computer History Museum (2012), http: / /www. computerhistory.org/atchm/make-software-changethe-world/

4. Report: $90 \%$ of Waking Hours Spent Staring at Glowing Rectangles. The Onion (June 15, 2009), http: / /www. theonion. com/articles/report-90-of-wakinghours-spent-staring-at-glowing, 2747/

5. Maslow, A.H.: A theory of human motivation. Psychological Review 50(4), 370-396 (1943)

6. Blum, A.: Tubes: A Journey to the Center of the Internet. Ecco (2012) 